\title{
Epidermolysis bullosa simplex: a paradigm for disorders of tissue fragility
}

\author{
Pierre A. Coulombe, ${ }^{1,2,3}$ Michelle L. Kerns, ${ }^{2}$ and Elaine Fuchs ${ }^{4,5}$ \\ 1Department of Biochemistry and Molecular Biology, Bloomberg School of Public Health, and 2Department of Biological Chemistry and \\ ${ }^{3}$ Department of Dermatology, School of Medicine, Johns Hopkins University, Baltimore, Maryland, USA. \\ ${ }^{4}$ Laboratory of Mammalian Cell Biology and Development and 5 Howard Hughes Medical Institute, Rockefeller University, New York, New York, USA.
}

\begin{abstract}
Epidermolysis bullosa (EB) simplex is a rare genetic condition typified by superficial bullous lesions that result from frictional trauma to the skin. Most cases are due to dominantly acting mutations in either keratin 14 (K14) or K5, the type I and II intermediate filament (IF) proteins tasked with forming a pancytoplasmic network of 10-nm filaments in basal keratinocytes of the epidermis and in other stratified epithelia. Defects in K5/K14 filament network architecture cause basal keratinocytes to become fragile and account for their trauma-induced rupture. Here we review how laboratory investigations centered on keratin biology have deepened our understanding of the etiology and pathophysiology of EB simplex and revealed novel avenues for its therapy.
\end{abstract}

\section{Introduction to epidermolysis bullosa simplex}

Epidermolysis bullosa (EB) is a grouping of rare genetic conditions in which bullous lesions (fluid-filled cavities, or blisters, larger than $0.5 \mathrm{~cm}$ ) affecting primarily the skin arise after exposure to mechanical trauma (1). Three major forms of EB have been defined using clinical and histological criteria. The dystrophic, junctional, and simplex forms of EB are characterized by loss of tissue integrity in the upper dermis, at the dermo-epidermal interface, and within the epidermis, respectively (Figure 1) (2,3). With rare exceptions, EB simplex is inherited in an autosomal dominant fashion. Although EB simplex is the most frequently occurring form of EB (approximately 1 case per 25,000 live births), it also is the least severe $(2,4-6)$. In this Review, we summarize current knowledge of the etiology and pathophysiology of EB simplex, discuss what this condition tells us about the properties and roles of keratin, and outline progress toward therapeutic intervention.

In EB simplex, trauma-induced loss of tissue integrity consistently occurs within the basal layer of epidermal keratinocytes (Figures 1 and 2). The inherited defect renders basal keratinocytes fragile, causing them to rupture when the epidermis (and, in some cases, other stratified epithelia) is subjected to mechanical stress (Figures 1 and 2). Associated skin pigmentation anomalies can occur (see below), but terminal epithelial cell differentiation and epidermal barrier function appear normal.

Several clinical variants of EB simplex have been described. The most frequent and widely known variants - EB simplex-generalized (EBS-generalized; in which the distribution of blistering is "generalized" over the body), EB simplex-localized (in which the distribution of blistering is "localized," e.g., primarily restricted to hands and feet), and EB simplex Dowling-Meara (EBS-DM; in which blisters are also generalized but show a distinct "herpetiform" or clustered pattern) - differ primarily according to the distribution, frequency, and severity of skin blistering over the body (Table 1). These variants also show key ultrastructural differences

Conflict of interest: The authors have declared that no conflict of interest exists. Nonstandard abbreviations used: EB, epidermolysis bullosa; EBS-DM, EB simplex Dowling-Meara; EBS-generalized, EB simplex-generalized; EBS-localized, EB simplex-localized; EBS-MD, EB simplex with muscular dystrophy; EBS-Migr, EB simplex with migratory circinate erythema; EBS-MP, EB simplex with mottled pigmentation; $\mathrm{IF}$, intermediate filament; $\mathrm{K}$, keratin.

Citation for this article: J. Clin. Invest. 119:1784-1793 (2009). doi:10.1172/JCI38177.
(Figure 3) and vary in the involvement of other epithelia and their prognosis (Table 1). Other forms of EB simplex are less frequent (e.g., EB simplex-autosomal recessive [EBS-AR], which resembles EBS-generalized but is recessively inherited) and/or exhibit additional clinical features (Table 1; see also ref. 7). EB simplex with mottled pigmentation (EBS-MP) is characterized by anomalies in skin pigmentation, while EB simplex with muscular dystrophy (EBS-MD) is accompanied by a progressive, limb-girdle type of muscular dystrophy (Table 1) $(3,7,8)$. Despite the degree to which clinical presentation varies (Table 1$)(2,3,6,9)$, all variants of $\mathrm{EB}$ simplex are caused by genetically determined defects in intracellular proteins whose function is to provide essential structural support in keratinocytes of the epidermis and related tissues $(10,11)$.

Most cases of EB simplex result from mutations affecting either keratin 14 (K14) or K5, the type I and type II intermediate filament (IF) proteins, respectively, expressed in basal keratinocytes in the epidermis and related complex epithelia (12-14) (Figure 1). In their normal state, K14 and K5 form type I/type II IF protein heterodimers (Figure 1), thousands of which then assemble into a 10-nm-wide cytoskeletal IF (15-17). Because of the heteropolymeric structure of keratin filaments, mutations in either the $K 5$ or the K14 gene can elicit a substantial fraction of the broad clinical spectra seen in EB simplex (Figure 3 and below). One exception is EBS$\mathrm{MD}$, which is caused by mutations in the gene encoding plectin, a cytolinker protein responsible for integrating various cytoskeletal and cell-adhesive elements into a functionally unified network (18, 19). Mutations in the gene encoding collagen, type XVII, alpha 1 (COL17A1), a hemidesmosomal plaque protein required for tight adherence of basal keratinocytes to the basal lamina, account for a special subset of patients with elements typical of both EB simplex and $\mathrm{EB}$ junctional $(20,21)$. Additional examples of rare forms of EB simplex that are linked to genes other than K5 and K14 are discussed in Fine et al. (7).

EB simplex has the distinction of being the first disorder shown to be caused by mutations in a gene encoding an IF protein and also the first epithelial (skin) fragility condition to have its etiology revealed, in the early 1990 s $(22,23)$. Despite the considerable progress made since then, developing successful therapies for EB simplex has proven to be challenging. There is reason to be cautiously optimistic, however, since recent discoveries made in studies of its pathophysiology have led to new ideas for therapy. 


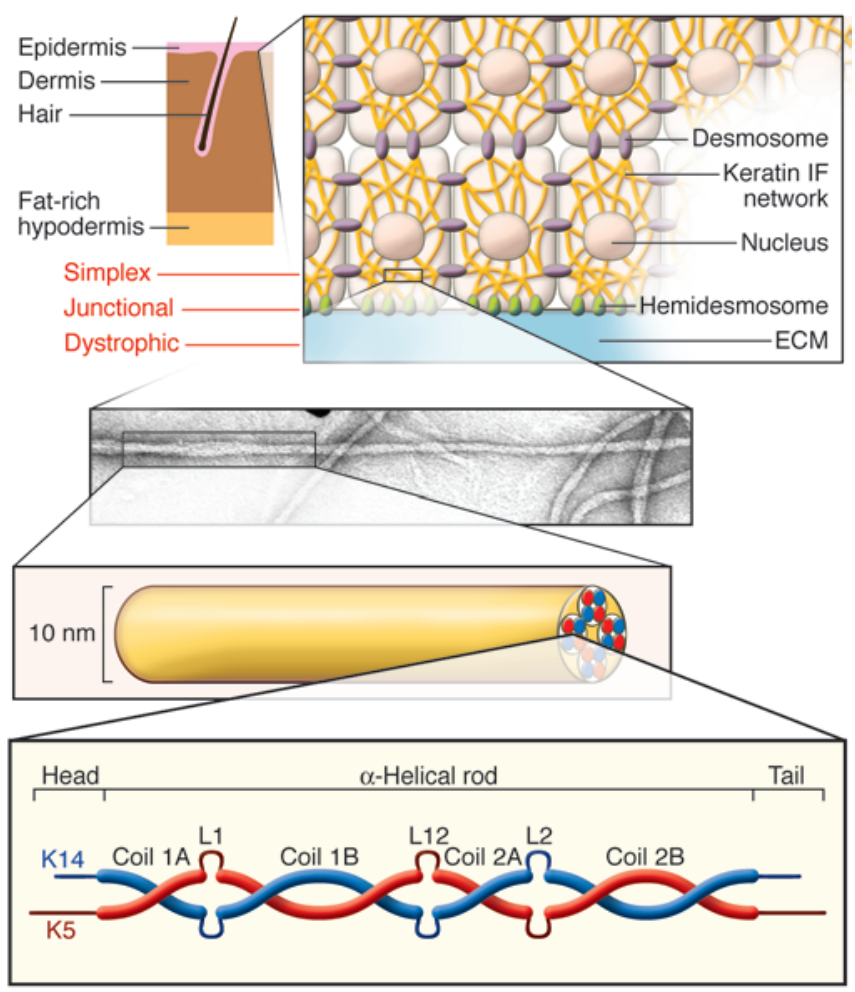

\section{From the bench to the clinic: reverse genetics, mouse models, and EB simplex}

By the late 1980s, many ideas had surfaced in the literature to account for the etiology of EB simplex and, in particular, for the fragile character of basal keratinocytes. Many of these ideas could be assigned to one of two broad possibilities: a misregulated or defective enzyme; or a defect in a structural component $(4,5)$. The concept of defects in keratin protein or filaments per se was certainly not at the forefront (5). Given the breadth and heterogeneity of the clinical features of EB simplex (Table 1) and the lack of a clear function for IFs at the time, there was no obvious reason to draw a link between the disorder and this cytoskeletal network.

The cloning and sequencing of epidermal keratins and the analysis of their secondary structure $(13,15,24,25)$ laid the foundation for elucidating the key assembly determinants in K14 and K5 via systematic deletion mutagenesis. Initial studies of this kind established that K14 deletion mutants missing small portions of either end of the central rod domain (Figure 1) markedly altered

\section{Figure 2}

Skin fragility in EB simplex and mouse models thereof. (A) Example of trauma-induced bullous skin lesions (arrows) in the feet of a 2-monthold child diagnosed with EB simplex. Courtesy of Bernard Cohen (Johns Hopkins School of Medicine; photo copyright DermAtlas). (B) Massive skin blistering as seen in a K14-null mouse neonate. Front paws and facial area are severely affected (arrows). (C) A control littermate exhibits intact skin. (D and E) Micrographs from H\&E-stained histological sections prepared from front paws of 2-day-old K14-null (D) and wild-type (E) mice. Fluid-filled blisters are obvious in the K14-null sample. Loss of epidermal integrity occurs near the basal layer of keratinocytes, the defining characteristic of EB simplex. The boxed region in E indicates 3 basal keratinocytes. hf, hair follicles. Scale bar: $100 \mu \mathrm{m}$.

\section{Figure 1}

Introduction to the epidermis, keratin filaments, and EB simplex. Schematic representation of skin tissue and detailed view of the bottom portion of the epidermis, highlighting the cytoplasmic network of keratin IFs attached to hemidesmosome cell-ECM and desmosome cell-cell contacts in basal keratinocytes. The plane of tissue rupture seen in the simplex, junctional, and dystrophic forms of EB are highlighted. The molecular configuration of the K5/K14 coiled-coil heterodimer, the smallest subunit participating in the formation of $10-\mathrm{nm}$ IFs, is shown in a schematic manner. The main secondary structure elements are: $\mathrm{N}$-terminal head and $\mathrm{C}$-terminal tail domains; $\alpha$-helical coils 1A, 1B, 2A, and 2B; and linkers L1, L12, and L2.

the architecture of the endogenous keratin IF network in cultured epithelial cells, and did so in a dominant fashion $(26,27)$. In vitro polymerization assays involving purified recombinant keratin proteins provided key details about the impact and mode of action of such K14 deletion mutants (28) and subsequently K5 deletion mutants (29).

Relevance to EB simplex was ultimately revealed when select K14 deletion mutants were tissue-specifically expressed in transgenic mice by using the K14 promoter $(30,31)$. Briefly, these mice exhibited trauma-induced blistering in the epidermis and oral mucosa that began shortly after birth and closely approximated the key features of EB simplex (Figure 2). When interpreted in light of previous reports describing defects in keratin IF network architecture in basal keratinocytes from individuals with EB simplex, in situ (32-34) and in culture (35), the phenotype of these mice clearly suggested that EB simplex could arise from mutations affecting the protein-coding sequence of either K14 or K5 (30). Such mutations were indeed found shortly thereafter, as discussed below.

Detailed characterization of this first cohort of transgenic mouse lines, which expressed K14 mutants under the control of the K14
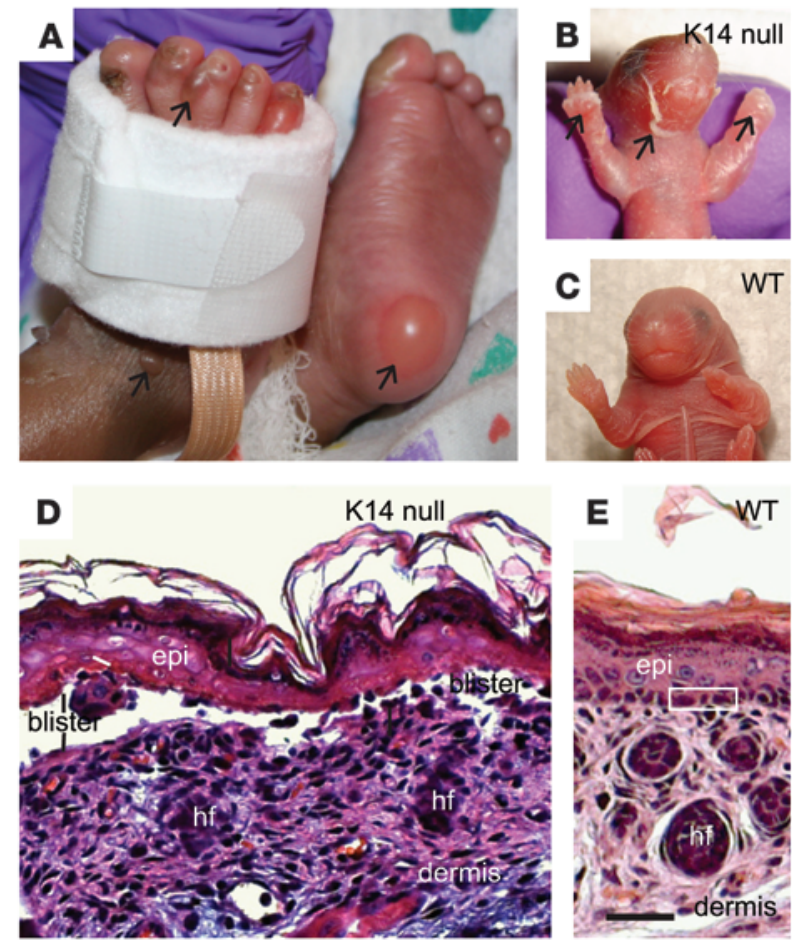


\section{Table 1}

EB simplex and other diseases caused by mutations in either K5 or K14

\begin{tabular}{|c|c|c|c|c|}
\hline EBS subtype ${ }^{A}$ & Distinguishing features & Onset & Target genes & $\begin{array}{l}\text { Original clinical } \\
\text { description }\end{array}$ \\
\hline EBS-Iocalized & $\begin{array}{l}\text { Formerly known as Weber-Cockayne-type EBS. } \\
\text { Blistering usually limited to hands and feet but can } \\
\text { occur at sites of repeated trauma; often associated } \\
\text { with palmoplantar keratoderma; worsens in } \\
\text { warmer months. }\end{array}$ & $\begin{array}{l}\text { Infancy, } \\
\text { early childhood, } \\
\text { adulthood }\end{array}$ & $\begin{array}{l}\text { Most frequently } K 5 \text {; } \\
\text { less frequently, } K 14\end{array}$ & 119,120 \\
\hline EBS-generalized & $\begin{array}{l}\text { Formerly known as Koebner-type EBS. Blisters } \\
\text { predominantly on hands and feet, but blistering is } \\
\text { often generalized; absence of large tonofilaments in } \\
\text { basal keratinocytes on electron microscopy; } \\
\text { worsens in warmer months. }\end{array}$ & $\begin{array}{l}\text { Birth or } \\
\text { infancy }\end{array}$ & $\begin{array}{l}K 5(C \text {-terminal } \\
\text { region and L2 linker } \\
\text { domain); K14 }\end{array}$ & 121 \\
\hline EBS-DM & $\begin{array}{l}\text { This form of EBS retained its original designation. } \\
\text { Widespread and severe blistering; herpetiform and } \\
\text { hemorrhagic blisters; frequent mucosal involvement; } \\
\text { progressive palmoplantar keratoderma; nail dystrophy } \\
\text { and milia; hyper- and hypopigmentation may occur; } \\
\text { may improve with heat or fever. }\end{array}$ & Birth & $\begin{array}{l}\mathrm{K} 5, \mathrm{~K} 14 \text { (at } \mathrm{N} \text { - or } \\
\mathrm{C} \text {-terminal ends of } \\
\text { the rod domain) }\end{array}$ & 122 \\
\hline EBS-AR & $\begin{array}{l}\text { Very rare variant. Largely similar to EBS-generalized, } \\
\text { though the frequency of blistering may be lower. }\end{array}$ & Infancy & K14 & $\begin{array}{l}\text { Ref. } 66 \text { provided the } \\
\text { first report of mutation }\end{array}$ \\
\hline EBS-MP & $\begin{array}{l}\text { Skin blistering with mottled pigmentation of trunk and } \\
\text { limbs; punctate palmoplantar keratoderma; } \\
\text { nail dystrophy. }\end{array}$ & $\begin{array}{l}\text { Birth or } \\
\text { infancy }\end{array}$ & $\begin{array}{c}\text { K5 (Pro24 } \rightarrow \text { Leu } \\
\text { mutation in head } \\
\text { domain); K14 }\end{array}$ & 123 \\
\hline EBS-Migr & $\begin{array}{l}\text { Very rare variant; formerly known as EBS with migratory } \\
\text { circinate erythema. Annular migratory multiple erythema } \\
\text { circinatum; multiple vesicles on the hands, feet, and legs; } \\
\text { lesions heal with brown pigmentation but no scarring. }\end{array}$ & Birth & K5 (tail domain) & 76 \\
\hline DDD & Reticular hyperpigmentation on flexure surfaces. & After puberty & K5 haploinsufficiency & 124 \\
\hline NFJS & $\begin{array}{l}\text { Reticular hyperpigmentation that disappears over time; } \\
\text { hypohidrosis; palmoplantar keratoderma; } \\
\text { absent fingerprint lines. }\end{array}$ & Birth & K14 (head domain) & 125 \\
\hline
\end{tabular}

AAdditional EB simplex (EBS) subtypes, caused by mutations in genes other than $K 5$ and $K 14$, have been documented and are more rare. See Fine et al. (7) for information on those, along with a justification of the classification of EBS disease subtypes. EBS-AR, EB simplex autosomal recessive; DDD, Dowling-Degos disease; NFJS, Naegeli-Franceschetti-Jadassohn syndrome.

promoter $(30,31)$, also provided a biological framework for many heretofore misunderstood features of EB simplex (Table 2). First, in addition to dominantly disrupting keratin IF structure, mutations in the K14 rod domain (Figure 1) can elicit the formation of aggregates of amorphous proteins in the cytoplasm (30,31,36). Such aggregates are diagnostic of the most severe form of EB simplex (EBS-DM; see Table 1 and Figure 3) and are immunopositive for K5 and K14 $(22,37)$. Second, onset of disease occurs shortly after birth, partly reflecting the embryonic onset of K5 and K14 gene expression $(38,39)$ along with the protected milieu experienced by the human fetus up until birth. Third, the broad range of clinical severity typifying EB simplex in humans can be mimicked in mouse skin tissue by expressing K14 experimental mutants having either a mild, moderate, or severe impact on keratin IF assembly in vitro (31). This finding helped dismiss the idea that variants such as EBS-DM and EBS-localized (Table 1) have a distinct etiology. Fourth, the ability of blisters to heal leaving no scar distinguishes EB simplex from EB junctional and EB dystrophic $(2,9)$. From the observation that the wound-inducible keratins K6, K16, and K17 are induced (as expected) in keratinocytes populating the margins of epidermal lesions, Coulombe et al. (31) suggested these kera- tins could compensate for the inherited defect in either K5 or K14, allowing for normal epithelialization to occur (see Devising an effective therapy for EB simplex: challenges and opportunities below for further discussion). Fifth, these early findings in mice suggested that similar defects in other keratin proteins should elicit analogous deficiencies in relevant epithelial cell types. This was later shown to be the case via the tissue-specific expression of a deletion mutant of $\mathrm{K} 10$, a keratin expressed in terminally differentiating keratinocytes of the epidermis and related cornifying epithelia (14), in transgenic mice. The trauma-induced cell fragility in the suprabasal portion of epidermis of these mice was similar to the human condition epidermolytic hyperkeratosis (36). Mutations in the $K 1$ and $K 10$ genes were later found in patients with this condition (40-42).

Mice homozygous null for K14 (Figure 2), K5, or plectin also displayed the key features of EB simplex (with accompanying muscle defects in the case of plectin), thus revealing that cell fragility is largely a "loss-of-function" phenotype (Table 2). Lloyd et al. (43) showed that the lesser degree to which the esophagus is affected relative to epidermis in newborn K14-null mice correlates with higher levels of K15, a type I keratin related to K14, in the esophagus. The presence of small amounts of K15, but not of a type II keratin related 

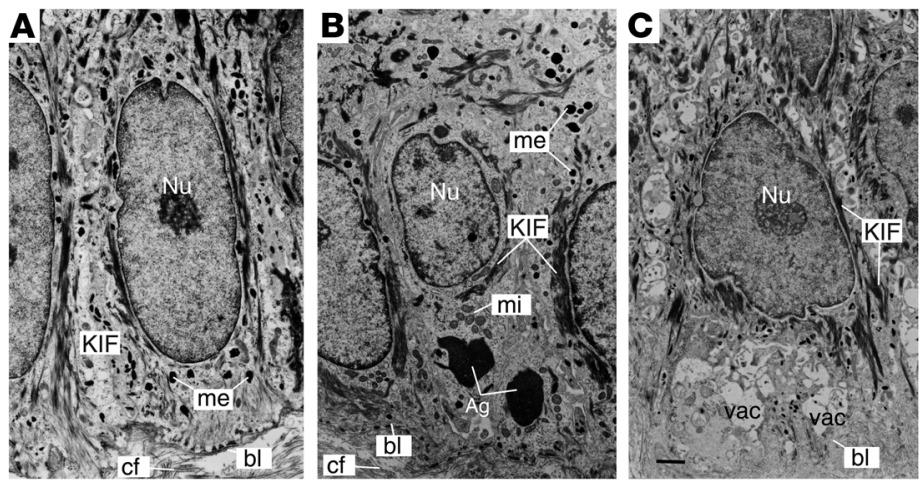

\section{Figure 3}

Ultrastructure of epidermal basal keratinocytes in EB simplex. These transmission electron micrographs were obtained from ultrathin sections prepared from epoxy-embedded intact (nontraumatized) human skin that had been fixed for routine electron microscopy. (A) Sample from a normal individual. Note the columnar shape of the basal keratinocyte shown and the prominence of keratin IF (KIF) bundles and of dispersed melanin granules (me) in the cytoplasm. (B) Sample from an individual with EBS-DM. Note the two prominent aggregates $(\mathrm{Ag})$ in the cytoplasm, between the nucleus $(\mathrm{Nu})$ and basal lamina (bl). This cell also features KIF bundles, although they seem small compared with those in basal keratinocytes from normal individuals. (C) Sample from an individual with EBS-localized. Note the presence of many vacuoles (vac) in the cytoplasm, between the nucleus and basal lamina in the basal keratinocyte shown. This cell, which does not show obvious defects in KIF content or distribution, may correspond to a microblister. cf, collagen fibers; mi, mitochondria. Scale bar: $1 \mu \mathrm{m}$. Adapted from ref. 5.

to K5, likely accounts for the markedly more severe blistering of skin, and earlier death, seen in K5-null mice compared with K14null mice (43-45). A compensatory role for K15 was also invoked in studies of individuals whose genomes bear the equivalent of a K14null mutation $(46,47)$. These first hints pointing to the existence of functional redundancy within the keratin multigene family were thereafter formally confirmed when targeted expression of K16 in basal keratinocytes of the epidermis was shown to substantially reduce skin blistering and to prevent neonatal death in K14-null mice (48). This concept has implications for therapy (see Devising an effective therapy for EB simplex: challenges and opportunities below).

Finally, a mouse model with conditional expression of a mutant K14 allele in basal keratinocytes of the epidermis (49) also provided important insight into EB simplex and its therapy. Studies of this mouse strain showed that, as could be predicted from in vitro assays (28), the impact of strong dominant-negative mutant keratin proteins is mitigated when the wild-type protein is reintroduced in vivo. Cao, Roop, et al. (49) also showed that wild-type keratinocytes have a growth advantage over those expressing mutant keratin in skin epithelia in vivo. This finding has obvious implications for gene therapy. Also of relevance here is the "revertant mosaicism" noted in the skin of individuals with EB simplex in which a "second hit" (frameshift mutation) in the same K14 allele generates the equivalent of a null allele (50), or a "corrected" allele (51), thus negating the impact of an otherwise strong dominant-negative mutation.

\section{Some key lessons learned from genotype-phenotype correlations}

A comprehensive and useful database of human keratin mutations, and associated diseases, is maintained at the University of Dundee (see www.interfil.org and ref. 11). K5 and K14 mutations account for more than $36 \%$ of all keratin disease-associated mutations characterized thus far (278 of 765 reports), and together they are second only to mutations in $L M N A$, the gene encoding lamins $\mathrm{A}$ and $\mathrm{C}$ (nuclear IF proteins), with regard to documented disease-causing mutations in an IF protein-encoding gene (11). Figure 4 summarizes the frequency (Figure 4A) and distribution (Figure 4B) of mutations in $\mathrm{K} 5$ and $\mathrm{K} 14$ proteins as a function of EB simplex variants. Most of these mutations are encoded by dominantly acting missense alleles. EBS-DM has been genetically characterized more frequently than any other variant of EB simplex, predominantly because the mutations often reside within the same short and highly conserved stretches of sequence within keratins, making them easier to identify $(2,3,6)$.

Some general lessons can be drawn from examining the data in Figure 4. For the EBS-localized, EBS-generalized, and EBS-DM variants, a strong concordance exists among the position and nature of the mutation in the target keratin protein, the extent to which it disrupts keratin IF assembly and structure (when tested in vitro or through transfection in cultured cells), and, ultimately, the severity of clinical presentation (52-57). A corollary to this principle is that the nature of the mutation affecting K5 or K14 defines the sensitivity threshold that the epithelium displays toward frictional trauma, thereby contributing to whether the symptoms are local (e.g., EBS-localized) or generalized (e.g., EBS-generalized and EBS-DM).

Mutations altering highly conserved residues located within the so-called helix initiation and helix termination motifs, in either K5 or K14, are overwhelmingly associated with EBS-DM (Figure 4). Further, markedly more cases of EBS-DM are caused by K14 mutations than K5 mutations, a fact that is traceable to the presence of a mutational "hot spot" in codon 125, which encodes an arginine residue located in the helix initiation motif of coil $1 \mathrm{~A}(22,58,59)$. The extraordinarily high frequency of mutations (more than $29 \%$ of all reported disease-causing mutation events in K14; ref. 11) at this arginine-encoding codon and the corresponding (conserved) codon in other type I keratins and non-keratin IF proteins $(8,11)$ probably follows deamination of methylated cytosine in the context of a CPG dinucleotide (known as the most frequent mutation-causing mechanism in the human genome; ref. 60). Several lines of evidence underscore the crucial role of this arginine residue (and other highly conserved residues within the helix initiation and helix termination motifs; see Figure 4) in keratin IF assembly and function $(22,52,61,62)$.

Conversely, the mildest variant of EB simplex, EBS-localized, most frequently arises because of missense mutations affecting residues located in the nonhelical head and linker domains of the keratin, particularly K5 (Figure 4). The primary structure of these domains is less well conserved than that of the helix initiation and helix termination motifs as well as other $\alpha$-helical portions of the central rod domain (see Figure 1 and ref. 63). Mutations in these domains are generally less consequential for IF assembly and function $(52-54,64,65)$. Why the analogous head and linker regions of K14 are not as frequently targeted for mutation as they are in $\mathrm{K} 5$ is not clear. One possibility, which is supported by genetic evidence, is that such mutations would behave recessively (see EBSAR in Figure 4B; ref. 11). Another factor is the presence of K15 in 
Table 2

Main features of EB simplex: solved elements and unsolved mysteries

\author{
Feature \\ Solved elements \\ Loss of tissue integrity occurs intracellularly \\ Mutations can occur in either K5 or K14 \\ Disease is (usually) dominantly inherited
}

Onset of blistering at, or after, birth

Broad range of disease severity, including localized vs. generalized blister distribution Stratified epithelia other than the epidermis
are occasionally targeted

Blisters can heal without scarring

There are cases of EBS-like disease in which the $K 5$ and $K 14$ genes are intact

\section{Unsolved mysteries}

Seasonal susceptibility to blistering, with increased frequency during the summer

Age-related decrease in frequency and/or severity of skin blisters

Herpetiform (clustered) distribution of skin blisters in EBS-DM and EBS-Migr variants

Loss of basal keratinocyte integrity occurs between hemidesmosomes and nucleus of mutant keratin-expressing keratinocytes

Select forms of EBS are associated with a skin pigmentation phenotype
Comment

$\mathrm{K} 5$, K14 are intracellular proteins (as is plectin, which is mutated in EBS-MD).

The basic subunit structure of the keratin filament is a heterodimer of a type I and type II keratin.

Keratin IF assembly is a multistep reaction; mutations in $K 5$ and $K 14$ do not prevent formation of small-sized mutant subunits that get incorporated in the growing fibrous polymer.

K5 and K14 are first expressed at the onset of stratification in the embryonic ectoderm. However, keratin filaments are not required for genesis and differentiation of epidermis, but rather affect the overall mechanical integrity of the basal keratinocytes. Also, a substantial amount of trauma is usually required to elicit a skin blister.

K5 and K14 proteins feature a modular, tripartite substructure, with the various subdomains making a differential contribution to IF assembly; most mutations are small changes (e.g., missense) and can affect various portions of $\mathrm{K} 5$ and $\mathrm{K} 14$; varying amounts of frictional trauma are required to expose the weakness of a defective K5/K14 IF network, depending on mutant.

$K 5$ and $K 14$ genes are expressed in the progenitor basal layer of all stratified and pseudostratified epithelia; varying amounts of $\mathrm{K} 15$, a type I IF protein related to K14, are expressed in internal stratified epithelia; internal epithelia are exposed to less mechanical stress compared with the epidermis.

Basal lamina remains intact during and after blistering; blister healing involves the induction of keratins related to K5 (K6a and K6b) and K14 (K16 and K17). In addition, without continual mechanical trauma, the mutant basal keratinocytes adopt a grossly normal physiology.

K5-K14 heteropolymers interact with other proteins for function (e.g., plectin); mutations in such proteins can elicit EBS-like skin blistering.

Do (most) keratin mutations behave in a temperature-sensitive fashion?

Likely due to a combination of behavioral adaptation and development of cellular and molecular compensatory mechanisms over time. It has been suggested that this may at times be due to "spontaneous" revertant mutations.

Related to the presence of intracellular aggregates of mispolymerized keratin and/or to inflammation?

Is this region of the cell a "hot spot" for keratin subunit integration in newly forming filaments? Interesting correlate with live imaging studies (see ref. 62).

There is an newly emerging role for cytoplasmic IF proteins in regulating intracellular transport; in this instance, it would affect melanin pigments. basal keratinocytes $(43,66)$. Although not sufficient to temper the consequences of severe K14 mutations, wild-type K15 might be expected to positively and selectively ameliorate subtle K14-mediated defects in the IF network of basal keratinocytes.

The other classical EB variant, EBS-generalized, which is intermediate in severity between EBS-localized and EBS-DM, is also frequently associated with mutations in the helix initiation and helix termination motifs but also shows a greater frequency of mutations mapping elsewhere in the rod domain than EBS-DM (Figure 4). The phenotype-genotype correlation argument provided here relies heavily on "mutation location" in either K5 or K14; of course, the nature of the mutation at any given site can also weigh heavily on the consequences for overall protein function. Mutations causing EBS-MP and EB simplex with migratory circinate erythema (EBS-Migr), two nonclassical variants of EB simplex (Table 1), show a predilection for the head and tail domains of K5, respectively (Figure 4). The implications of this finding are discussed in the next two sections.

\section{Pathophysiology of EB simplex:} straightforward, and yet ...

Elucidating the genetic basis for EB simplex created an opportunity to reexamine its pathophysiology (see Table 2) and investigate, on a de novo basis, the causal relationship among keratin assembly, IF network architecture, and epithelial cell integrity.

Studies carried out in relevant mouse models confirmed that frictional trauma, often in a repeated fashion, is required to expose the fragility of basal keratinocytes and elicit bullous skin lesions. Subsequent biophysical studies conducted on keratin IFs, both when reconstituted in vitro and in cultured cells ex vivo, strongly suggested that mutant keratin-expressing basal keratinocytes are mechanically softer due to defects in the architecture of the IF network (61). Relative to filaments reconstituted in vitro from wildtype K5 and K14 proteins, those containing EB simplex-causing K14 mutations (e.g., Arg125 $\rightarrow$ Cys; ref. 61) or K5 mutations (e.g., 1649delG; ref. 57) exhibit markedly lower elasticity under small (linear) deformation regimes and break readily when subjected 
A Frequency of mutations in $\mathrm{K} 5$ and $\mathrm{K} 14$ vs. EB simplex variant

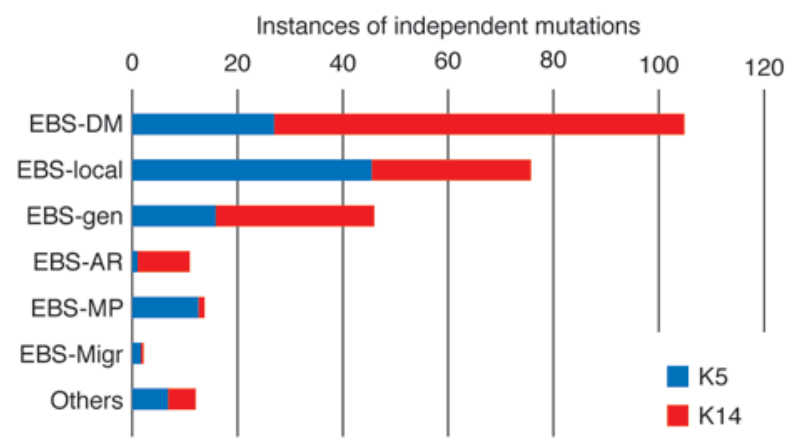

B Location of mutations in $\mathrm{K} 5$ and $\mathrm{K} 14$ vs. EB simplex variant

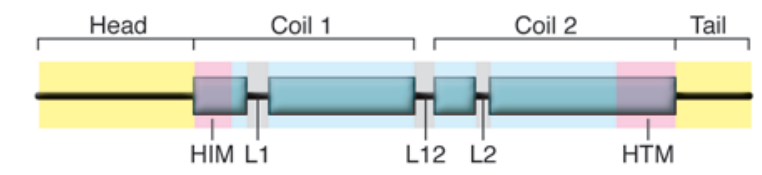

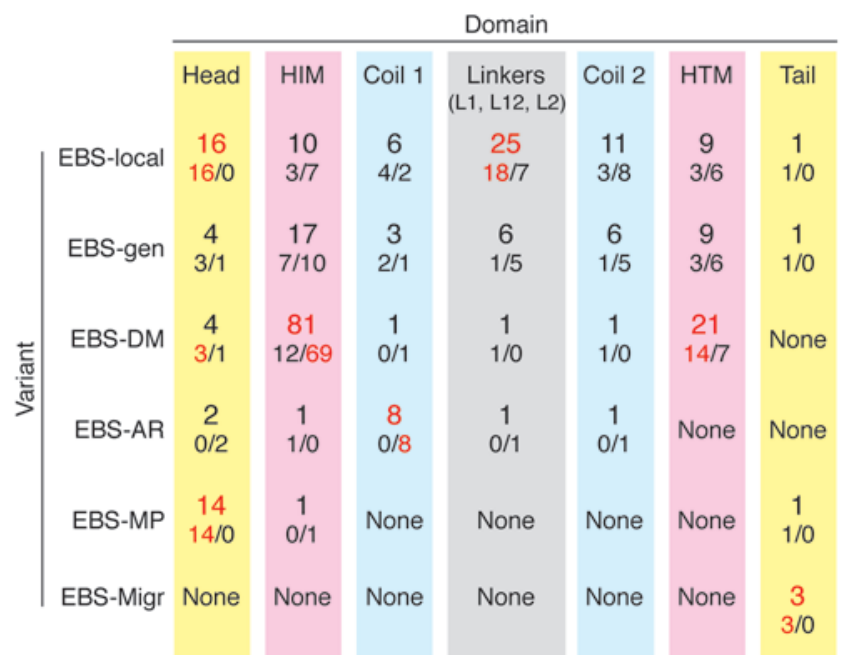

to progressively larger (nonlinear) amounts of shear stress. The deficiency observed is markedly enhanced when such filaments are crosslinked into a network, a circumstance that increases the elasticity of wild-type K5/K14 heteropolymers by 500-fold (61), depending on concentration (67).

Beil et al. (68) showed that collapse of keratin IFs around the nucleus, in a fashion characteristic of many mutant keratinexpressing cells, causes a dramatic softening of the cytoplasm in cultured epithelial cells. When conducting live imaging studies of cultured skin keratinocytes, Werner et al. (62) found that assembly subunits containing wild-type K14 incorporate within "growing" filaments in a specific zone of the peripheral cytoplasm; in contrast, subunits containing a K14 Arg125 $\rightarrow$ Cys mutant protein fail to do so (62). The latter finding is of interest given the earlier observation that trauma-induced rupture of basal keratinocytes often occurs in a specific area of the cytoplasm, between hemidesmosomes and the nucleus, in EB simplex skin (32) and mouse models thereof (22). Much progress has thus been made from a handful of biophysical and live imaging studies, so that future efforts of this type could transform our understanding of how the keratin IF network supports epithelial cell integrity in vivo.

\section{Figure 4}

Distribution of mutations in $K 5$ and $K 14$ as a function of disease variant in EB simplex. (A) Histogram depicting the number of cases of mutations in $K 5$ and $K 14$ as a function of EB simplex variant. The category "Others" corresponds to the aggregate of most other variants of the disease, excluding EBS-MD (see Table 1). (B) Distribution of mutations as a function of position within $\mathrm{K} 5$ and $\mathrm{K} 14$ and clinical variant of the disease. See main text and Figure 1 for information about keratin protein secondary structure. Each entry consists of three numbers: the top one is the total number of mutations; the bottom left number is the subset of these mutations that affect $\mathrm{K} 5$; and the bottom right number is the subset of these mutations that affect K14. "None" indicates the absence of mutations for this region of $K 5$ or $K 14$. Red numbers convey the occurrence of a bias toward either $\mathrm{K} 5$ or $\mathrm{K} 14$. The data are derived from ref. 11. EBS-AR, EB simplex autosomal recessive; EBSgen, EBS-generalized; EBS-local, EBS-localized; HIM, helix initiation motif; HTM, helix termination motif.

The presence of cytoplasmic aggregates containing mispolymerized mutant keratin proteins is the defining characteristic of EBS-DM (Table 1 and Figure 3) and may worsen the impact of dominant-negative mutations. Mice made to express aggregationprone K14 mutants $(30,31,49)$ exhibit an earlier onset of disease and more severe blistering and die earlier than K14-null mice (43). Analogously, the EB simplex phenotype exhibited by individuals null for K14 is milder than that of autosomal-dominant EBS-DM $(46,47,69)$. The strong missense alleles characteristic of EBS-DM likely curtail the beneficial influence of any wild-type keratin (e.g., $\mathrm{K} 15$ in basal keratinocytes), as these also become incorporated into the defective assembly aggregates.

Additionally, when the misfolded protein response fails to resolve these aggregates, they may overwhelm the protein homeostasis apparatus of the cell $(70,71)$. This could lead to cellular stress $(72,73)$ and influence the cell and tissue phenotypes in vivo. Cytoplasmic aggregates of mispolymerized IF proteins are characteristic of many disorders caused by mutations in genes encoding non-keratin IF proteins (8). Alexander disease, for instance, is a devastating neurological condition caused by missense mutations in the gene encoding the type III IF protein glial fibrillary acidic protein (GFAP) (74). Mutant GFAP-containing aggregates, readily seen in histology sections, are a cardinal feature of this condition. Such astrocyte-specific aggregates may be the source of the non-cell-autonomous pathophysiology of this condition, i.e., the Alexander disease phenotype may also reflect anomalies in CNS cell types that do not express mutant GFAP (75).

Does inflammation play an important role in the EB simplex phenotype? The clinical and experimental evidence in this regard is equivocal. In EBS-Migr (Table 1) (76), skin blisters show a distinct belt-like erythema, and their margins are migratory even in traumafree skin, suggesting a role for inflammation. In addition, there are conflicting reports as to whether the Arg125 $\rightarrow$ Cys mutation in $K 14$, which causes EBS-DM, results in increased TNF- $\alpha$ secretion and increased susceptibility to TNF- $\alpha$-induced apoptosis in human keratinocytes $(77,78)$. Lugassy et al. (79) reported that $K 14$ haploinsufficiency results in increased susceptibility of keratinocytes to TNF- $\alpha$-induced apoptosis and suggested that this plays a key role in the pathogenesis of Naegeli-Franceschetti-Jadassohn syndrome (NFJS) (Table 1), extending previous work on EBS-DM mutations by Yoneda et al. (80). In contrast, Lu et al. (78) detected higher levels of IL- 6 , IL-1 $\beta$, and chemokines, but normal levels of TNF- $\alpha$, in 
the skin of newborn $K 5$-null mice. The latter mice survived only marginally longer after birth (up to 8 hours compared with less than 2 hours) when treated with the antiinflammatory agent doxycycline (78). Related to this, sulforaphane, another small molecule with antiinflammatory properties, does not substantially prolong the life of $K 5$-null mice, although it reduces skin inflammation (45). Finally, conventional apoptosis does not occur in the epidermis of individuals with the most common variants of EB simplex, or in mouse models thereof $(45,78)$. Whether proinflammatory cytokines are produced as a secondary consequence of basal cell lysis, even when occurring on a microscopic scale (Figure 3), or are present before mechanical trauma and the ensuing blistering remains unclear and requires further investigation.

Further, certain clinical attributes of EB simplex still have no sound biological basis (Table 2). Topping the list of such attributes are two frequently seen phenomena: enhanced frequency of skin blistering during the warm season and age-related improvement in clinical symptoms $(2,7,9)$. On an anecdotal basis, bathing in cold water and, paradoxically, experiencing fever episodes seem to lessen the blistering in individuals with EB simplex (4). Although experimental evidence is still lacking, one possibility is that conditions that activate the heat shock/stress response may help to resolve the aggregates of misassembled keratins. Understanding the mechanistic basis for these phenomena, as well as others listed in Table 2, may lead to new insights into keratin and epithelial biology as well as innovative ideas for treatments for EB simplex.

\section{Human and mouse genetics suggest a role for keratin in modulating skin pigmentation}

A plethora of genetic findings in humans and mice have now formalized a new role for keratin in regulating skin pigmentation. Some of the key supporting evidence emerged from studies of unconventional forms of EBS as well as other disorders arising from mutations in either K5 or K14 (Table 1). Uttam et al. (81) discovered that a peculiar missense mutation, Pro2 $4 \rightarrow$ Leu, in the head domain of K5 causes EBS-MP, in which small (2- to 5-mm wide) hypo- or hyperpigmented spots confer a mottled appearance to the skin (Table 1). Several additional cases of EBS-MP were later traced to the same $K 5$ allele (11) (although it is important to note that the University of Dundee database has the Pro residue at position 25 in K5) and to distinct mutations in either $K 5$ (e.g., 1649delG; ref. 82) or K14 (e.g., Met119 $\rightarrow$ Thr; ref. 83). The 1649 delG allele of $K 5$ can also result in EBS-Migr, and this too is characterized by the appearance of hyper- or hypopigmented skin patches in adults (76). In addition, Betz et al. (84) have linked Dowling-Degos disease (DDD) (Table 1), which is characterized by reticulate hyperpigmentation and dark hyperkeratotic papules in skin flexural regions, to $K 5$ haploinsufficiency. Finally, dermatopathia pigmentosa reticularis and NFJS are two related dominantly inherited conditions featuring reticulate or mottled hyperpigmentation of the skin (Table 1 ) that are caused by frameshift mutations, which are located in the head domain of K14 and presumably result in haploinsufficiency (85). As for mouse-based evidence, Fitch et al. (86) recovered keratin mutant alleles from a random mutagenesis screen designed to identify "novel" genes involved in mouse coat color determination. They found that dominantly acting missense alleles in $K 2 E$ (Thr500 $\rightarrow$ Pro; ref. 86) and $K 1$ (Ser194 $\rightarrow$ Pro; ref. 87), two type II keratins expressed at high levels in the suprabasal differentiating layers of the epidermis, elicit a dark skin phenotype. Expression of these alleles in mouse skin also reproduces the keratinocyte fragility associated with similar mutations in the human orthologs, which cause epidermolytic hyperkeratosis $(86,87)$.

Although the pigmentation phenotypes characteristic of EBSMigr and epidermolytic hyperkeratosis could be an indirect consequence of cytoarchitectural defects precipitated by the expression of strong mutant keratin proteins, this is unlikely to account for the phenotype associated with either the Pro24 $\rightarrow$ Leu mutation in K5, which does not overtly disrupt 10 -nm IF assembly (81), or K5 haploinsufficiency (84). Skin pigmentation is the result of an intimate partnership between keratinocytes and neural crest-derived melanocytes, which are located in the basal layer of the epidermis (and hair matrix) (88). Membrane-bound melanosomes are manufactured in melanocytes and transferred to the cytoplasm of proximal keratinocytes, where their cargo (pigmented melanin granules) is released (Figure 3A). Other than pigment chemistry, the concentration and distribution of melanin in the keratinocyte cytoplasm are key determinants of skin pigmentation $(88,89)$. There is growing evidence showing that keratin proteins functionally interact with melanin pigments (10). The head domain of K5 was found to bind the dynein light chain in a Pro24-dependent fashion in a yeast two-hybrid screen (90), whereas expression of a K5 head domain fragment corresponding to the frameshift mutation in individuals with DDD results in colocalization with the dynein intermediate chain in cultured MCF-7 cells (84). Of note, dynein participates in the centripetal transport of melanin pigments to form a supranuclear cap in keratinocytes (91). Finally, the mocha mouse, which has a diluted coat and eye color phenotype, lacks a functional $\delta$ subunit of the adaptor-like protein complex AP3 (92), which normally binds various IF proteins $(93,94)$. In-depth studies of how keratin proteins regulate melanosome import and/or melanin distribution within the cell will help define this newly emerging function and clarify the mechanism(s) underlying the phenotype of individuals with variants of EB simplex associated with altered pigmentation.

\section{Devising an effective therapy for EB simplex: challenges and opportunities}

Elucidating the genetic basis of EB simplex has had a significant impact on skin biology and dermatology. It established that inherited defects in a structural protein, even when small (e.g., a missense mutation), can ultimately compromise the function of the large array of interconnected intracellular and extracellular protein polymers tasked with maintaining the integrity of skin tissue. The genetic bases of a large number of single-gene disorders exhibiting skin epithelial fragility have been determined since then, and more than 70 conditions have now been associated with similar mutations in IF genes and proteins (11).

EB simplex arguably remains one of the most well-understood inherited bullous diseases. As discussed in this Review, thanks to contributions from researchers all over the world, we now know its etiology and benefit from a solid understanding of its pathophysiology. Pre- and postnatal genetic testing and counseling options are now available (95-97). There is one glaring area in which progress has lagged behind, and that is advancing the therapeutic options for patients that suffer from this psychologically and physically debilitating disorder. Treating EB simplex presents a special challenge because of the dominant mode of action of keratin mutations, the broad spectrum of mutations affecting either one of the two main genes targeted in this disease ( $K 5$ and $K 14$ ), 
and the intrinsically high cell turnover rate seen in the epidermis. These specific elements add to generic factors limiting the success and applicability of gene therapy approaches directed at either the DNA or RNA level $(49,98,99)$ and to the challenges associated with conducting a clinical trial in the context of a rare disease. The few formalized efforts to test therapies in EB simplex have yielded inconclusive results (100). The standard of care for EB simplex, i.e., minimizing trauma and preventing infections in healing blisters, remains preventive and palliative.

In vitro (28) and in vivo (49) studies have shown that the dominant-negative impact of mutant K14 proteins is mitigated by reintroduction of wild-type K14 protein. However, corrective intervention directed at the genetic code per se may not be practical as an effective means of treatment. One way to build up mechanical resiliency in trauma-sensitive epidermis (45) might be to exploit the partial functional redundancy known to exist among select keratins (101-103) and other IF proteins $(104,105)$ and to devise means to stimulate their endogenous expression in the skin of affected patients.

There is indirect yet compelling evidence that the scar-free healing of skin blisters in EB simplex is due, at least in part, to a "favorable" plane of tissue cleavage, which leaves the basal lamina intact (Figure 1), and to a rapid induction and subsequent accumulation of the so-called wound-repair keratins (K6, K16, and K17) in surviving keratinocytes located near the blister margins $(31,102)$. This rapid transcriptional switch is a hallmark of tissue repair in skin and other complex epithelia (106). A growing body of evidence suggests that the amount of structural support provided by IFs composed of these wound-repair keratins compares favorably with that provided by K5/K14 IFs (45, 48, 107-109). Given that these keratins are inducible by a variety of different agents, including retinoids (110) and growth-stimulatory factors (e.g., EGF; ref. 111), as well as injury, understanding more about the molecular mechanisms underlying their regulation might offer new insights into how one might control the expression of these genes for therapeutic purposes.

Some methods for achieving this goal are clearly not viable clinically. For example, constitutive activation of sonic hedgehog signaling induces K17 and rescues K14-null mice (45) but has marked oncogenic potential (112). A more promising possibility might be the use of the isothiocyanate sulforaphane, a small molecule that induces K16 and K17 expression in epidermal keratinocytes and that selectively reduces skin blistering and extends the lifespan of K14-null mice (45). This small chemical occurs naturally in high levels in a precursor form in broccoli sprouts and other cruciferous vegetables (113). Importantly, it is best known for its marked chemopreventive influence against a broad range of tumors, via its ability to foster Nrf2-dependent transcription (114). Broccoli sprout extracts, prepared under good manufacturing practice (GMP) conditions and calibrated for their bioactive sulforaphane content, have cleared phase I clinical trials (e.g., refs. 115-117) and are safe for use in human skin (118). This approach, designed to exploit a homeostatic response perfected by years of evolution, is worth further testing as a preventive measure for EB simplex, either alone or in combination with other treatments.

\section{Conclusions and future perspectives}

EB simplex, the first disorder shown to be due to mutations in an IF protein-encoding gene, continues to be an inspiring model for clinical and laboratory research on various genetic disorders involving IFs, single-gene epithelial fragility conditions, and likely other disorders. This disease paradigm illustrates the immense benefits afforded by starting with understanding protein biochemistry and function and then ascertaining physiological and disease relevance by genetically engineering mice. By taking this reverse genetic approach, researchers can systematically generate the tools to elucidate and better understand the etiology and pathophysiology of human diseases, as well as devise and test novel strategies for therapy.

Further progress in EB simplex (and related conditions) requires research breakthroughs at fundamental and applied levels. An example of the former is knowledge of IF structure with atomic resolution, without which it will continue to be difficult to define how small mutations alter IF assembly, structure, and function. Another breakthrough needed is a better understanding of the mechanism of IF assembly, and its spatial and temporal regulation, prevailing in living cells. Yet another is to understand how keratin IF networks are generated, maintained, and regulated in the cytoplasm of epidermal keratinocytes and other cell types. At the applied research level, key challenges are to learn how to access the genome of skin epithelial stem cells with sufficiently high efficiency and to manipulate it in a manner that serves the therapeutic objective while being neutral otherwise. Progress in this vein is needed to exploit in full the molecular genetic advances made toward gene therapy and allele-specific silencing. Infrastructure support and better access to genetically defined patients is also needed to assist in the testing of novel therapies for orphan diseases such as EB simplex.

\section{Acknowledgments}

The authors thank Bernard Cohen, Daryle DePianto, and Chang-Hun Lee for providing illustrations. Relevant work in P.A. Coulombe's laboratory is supported by grants from the NIH (AR42047 and AR44232) and the March of Dimes. E. Fuchs is an Investigator of the Howard Hughes Medical Institute. Relevant work in her laboratory is supported by grants from the NIH (AR27883 and AR31737).

Address correspondence to: Pierre A. Coulombe, Department of Biochemistry and Molecular Biology, Bloomberg School of Public Health, Johns Hopkins University, 615 N. Wolfe Street, W8041, Baltimore, Maryland 21205, USA. Phone: (410) 955-3671; Fax: (410) 955-2926; E-mail: pcoulomb@jhsph.edu.

\footnotetext{
1. Garg, A., Levin, N.A., and Bernhard, J.D. 2008 Approach to dermatological diagnosis. In Fitzpatrick's dermatology in general medicine. 7th edition. K. Wolf, et al., editors. McGraw-Hill. New York, New York, USA. 23-39.

2. Fine, J.D., et al. 2000. Revised classification system for inherited epidermolysis bullosa: report of the Second International Consensus Meeting on diagnosis and classification of epidermolysis bullosa. J. Am. Acad. Dermatol. 42:1051-1066.
}

3. Marinkovich, M.P., and Bauer, E.A. 2008. Inherited epidermolysis bullosa. In Fitzpatrick's dermatology in general medicine. 7th edition. K. Wolf, et al., editors. McGraw-Hill. New York, New York, USA. 505-516.

4. Cooper, T.W., Bauer, E.A., and Briggaman, R.A. 1987. The mechanobullous diseases (epidermolysis bullosa). In Fitzpatrick's dermatology in general medicine. 3rd edition. T.B. Fitzpatrick, et al., editors. McGraw-Hill. New York, New York, USA. 610-626. 5. Coulombe, P.A., and Fuchs, E. 1993. Epidermolysis bullosa simplex. Semin. Dermatol. 12:173-190.

6. Horn, H.M., and Tidman, M. J. 2000. The clinical spectrum of epidermolysis bullosa simplex. $\mathrm{Br}$. J. Dermatol. 142:468-472.

7. Fine, J.D., et al. 2008. The classification of inherited epidermolysis bullosa (EB): Report of the Third International Consensus Meeting on Diagnosis and Classification of EB. J. Am. Acad. Dermatol. 58:931-950.

8. Omary, M.B., Coulombe, P.A., and McLean, W.H.I. 
2004. Intermediate filament proteins and their associated diseases. N. Engl. J. Med. 351:2087-2100.

9. Paller, A.S. 2004. The complexities of epidermolysis bullosa "simplex". J. Invest. Dermatol. 122:vi-vii.

10. Gu, L.H., and Coulombe, P.A. 2007. Keratin function in skin epithelia: a broadening palette with surprising shades. Curr. Opin. Cell Biol. 19:13-23.

11. Szeverenyi, I., et al. 2008. The Human Intermediate Filament Database: comprehensive information on a gene family involved in many human diseases. Hum. Mutat. 29:351-360.

12. Fuchs, E., and Green, H. 1980. Changes in keratin gene expression during terminal differentiation of the keratinocyte. Cell. 19:1033-1042.

13. Fuchs, E.V., Coppock, S.M., Green, H., and Cleveland, D.W. 1981. Two distinct classes of keratin genes and their evolutionary significance. Cell. 27:75-84.

14. Fuchs, E. 1995. Keratins and the skin. Annu. Rev. Cell Dev. Biol. 11:123-153.

15. Hanukoglu, I., and Fuchs, E. 1983. The cDNA sequence of a type II cytoskeletal keratin reveals constant and variable structural domains among keratins. Cell. 33:915-924.

16. Coulombe, P.A., and Fuchs, E. 1990. Elucidating the early stages of keratin filament assembly. J. Cell Biol. 111:153-169.

17. Hatzfeld, M., and Weber, K. 1990. The coiled coil of in vitro assembled keratin filaments is a heterodimer of type I and II keratins: use of site-specific mutagenesis and recombinant protein expression J. Cell Biol. 110:1199-1210.

18. McLean, W.H., et al. 1996. Loss of plectin causes epidermolysis bullosa with muscular dystrophy: cDNA cloning and genomic organization. Genes Dev. 10:1724-1735.

19. Gache, Y., et al. 1996. Defective expression of plectin/HD1 in epidermolysis bullosa simplex with muscular dystrophy. J. Clin. Invest. 97:2289-2298.

20. Fontao, L. et al. 2004. Molecular consequences of deletion of the cytoplasmic domain of bullous pemphigoid 180 in a patient with predominant features of epidermolysis bullosa simplex. J. Invest. Dermatol. 122:65-72.

21. Pfendner, E., Rouan, F., and Uitto, J. 2005. Progress in epidermolysis bullosa: the phenotypic spectrum of plectin mutations. Exp. Dermatol. 14:241-249.

22. Coulombe, P.A., et al. 1991. Point mutations in human keratin 14 genes of epidermolysis bullosa simplex patients: genetic and functional analyses. Cell. 66:1301-1311.

23. Bonifas, J.M., Rothman, A.L., and Epstein, E.H., Jr. 1991. Epidermolysis bullosa simplex: evidence in two families for keratin gene abnormalities. Science. 254:1202-1205.

24. Hanukoglu, I., and Fuchs, E. 1982. The cDNA sequence of a human epidermal keratin: divergence of sequence but conservation of structure among intermediate filament proteins. Cell. 31:243-252.

25. Steinert, P.M., Rice, R.H., Roop, D.R., Trus, B.L., and Steven, A.C. 1983. Complete amino acid sequence of a mouse epidermal keratin subunit and implications for the structure of intermediate filaments. Nature. 302:794-800.

26. Albers, K., and Fuchs, E. 1987. The expression of mutant epidermal keratin cDNAs transfected in simple epithelial and squamous cell carcinoma lines. J. Cell Biol. 105:791-806.

27. Albers, K., and Fuchs, E. 1989. Expression of mutant keratin cDNAs in epithelial cells reveals possible mechanisms for initiation and assembly of intermediate filaments. J. Cell Biol. 108:1477-1493.

28. Coulombe, P.A., Chan, Y. M., Albers, K., and Fuchs, E. 1990. Deletions in epidermal keratins leading to alterations in filament organization in vivo and in intermediate filament assembly in vitro. J. Cell Biol. 111:3049-3064.

29. Wilson, A.K., Coulombe, P.A., and Fuchs, E. 1992. The roles of K5 and K14 head, tail, and R/K L L E
$\mathrm{G}$ E domains in keratin filament assembly in vitro. J. Cell Biol. 119:401-414.

30. Vassar, R., Coulombe, P.A., Degenstein, L., Albers, K., and Fuchs, E. 1991. Mutant keratin expression in transgenic mice causes marked abnormalities resembling a human genetic skin disease. Cell. 64:365-380.

31. Coulombe, P.A., Hutton, M. E., Vassar, R., and Fuchs, E. 1991. A function for keratins and a common thread among different types of epidermolysis bullosa simplex diseases. J. Cell Biol. 115:1661-1674.

32. Haneke, E., and Anton-Lamprecht, I. 1982. Ultrastructure of blister formation in epidermolysis bullosa hereditaria: V. Epidermolysis bullosa simplex localisata type Weber-Cockayne. J. Invest. Dermatol. 78:219-223.

33. Anton-Lamprecht, I. 1983. Genetically induced abnormalities of epidermal differentiation and ultrastructure in ichthyoses and epidermolyses: pathogenesis, heterogeneity, fetal manifestation, and prenatal diagnosis. J. Invest. Dermatol. 81(1 Suppl.):149s-156s.

34. Ito, M., Okuda, C., Shimizu, N., Tazawa, T., and Sato, Y. 1991. Epidermolysis bullosa simplex (Koebner) is a keratin disorder. Ultrastructural and immunohistochemical study. Arch. Dermatol. 127:367-372.

35. Kitajima, Y., Inoue, S., and Yaoita, H. 1989. Abnormal organization of keratin intermediate filaments in cultured keratinocytes of epidermolysis bullosa simplex. Arch. Dermatol. Res. 281:5-10.

36. Fuchs, E., Esteves, R.A., and Coulombe, P.A. 1992. Transgenic mice expressing a mutant keratin 10 gene reveal the likely genetic basis for epidermolytic hyperkeratosis. Proc. Natl. Acad. Sci. U. S. A. 89:6906-6910

37. Ishida-Yamamoto, A., et al. 1991. Epidermolysis bullosa simplex (Dowling-Meara type) is a genetic disease characterized by an abnormal keratinfilament network involving keratins K5 and K14. J. Invest. Dermatol. 97:959-968.

38. Kopan, R., and Fuchs, E. 1989. A new look into an old problem: keratins as tools to investigate determination, morphogenesis, and differentiation in skin. Genes Dev. 3:1-15.

39. Byrne, C., Tainsky, M., and Fuchs, E. 1994. Programming gene expression in developing epidermis. Development. 120:2369-2383.

40. Cheng, J., et al. 1992. The genetic basis of epidermolytic hyperkeratosis: a disorder of differentiationspecific epidermal keratin genes. Cell. 70:811-819.

41. Chipev, C.C., et al. 1992. A leucine $\rightarrow$ proline mutation in the $\mathrm{H} 1$ subdomain of keratin 1 causes epidermolytic hyperkeratosis. Cell. 70:821-828.

42. Rothnagel, J.A., et al. 1992. Mutations in the rod domains of keratins 1 and 10 in epidermolytic hyperkeratosis. Science. 257:1128-1130.

43. Lloyd, C., et al. 1995. The basal keratin network of stratified squamous epithelia: defining $\mathrm{K} 15$ function in the absence of K14. J. Cell Biol. 129:1329-1344.

44. Peters, B., Kirfel, J., Bussow, H., Vidal, M., and Magin, T.M. 2001. Complete cytolysis and neonatal lethality in keratin 5 knockout mice reveal its fundamental role in skin integrity and in epidermolysis bullosa simplex. Mol. Biol. Cell. 12:1775-1789.

45. Kerns, M.L., DePianto, D., Dinkova-Kostova, A. T., Talalay, P., and Coulombe, P. A. 2007. Reprogramming of keratin biosynthesis by sulforaphane restores skin integrity in epidermolysis bullosa simplex. Proc. Natl. Acad. Sci. U. S. A. 104:14460-14465.

46. Chan, Y., et al. 1994. A human keratin 14 "knockout": the absence of K14 leads to severe epidermolysis bullosa simplex and a function for an intermediate filament protein. Genes Dev. 8:2574-2587.

47. Jonkman, M.F., et al. 1996. Effects of keratin 14 ablation on the clinical and cellular phenotype in a kindred with recessive epidermolysis bullosa simplex. I. Invest. Dermatol. 107:764-769.

48. Paladini, R.D., and Coulombe, P.A. 1999. The func- tional diversity of epidermal keratins revealed by the partial rescue of the keratin 14 null phenotype by keratin 16. J. Cell Biol. 146:1185-1201.

49. Cao, T., Longley, M.A., Wang, X.J., and Roop, D.R. 2001. An inducible mouse model for epidermolysis bullosa simplex: implications for gene therapy. J. Cell Biol. 152:651-656.

50. Smith, F.J., Morley, S.M., and McLean, W.H. 2004. Novel mechanism of revertant mosaicism in Dowling-Meara epidermolysis bullosa simplex. J. Invest. Dermatol. 122:73-77.

51. Schuilenga-Hut, P.H., et al. 2002. Partial revertant mosaicism of keratin 14 in a patient with recessive epidermolysis bullosa simplex. J. Invest. Dermatol. 118:626-630.

52. Letai, A., et al. 1993. Disease severity correlates with position of keratin point mutations in patients with epidermolysis bullosa simplex. Proc. Natl. Acad. Sci. U. S. A. 90:3197-3201.

53. Chan, Y.M., Yu, Q.C., Fine, J.D., and Fuchs, E. 1993. The genetic basis of Weber-Cockayne epidermolysis bullosa simplex. Proc. Natl. Acad. Sci. U. S. A. 90:7414-7418.

54. Chan, Y.M., et al. 1994. Mutations in the non-helical linker segment L1-2 of keratin 5 in patients with Weber-Cockayne epidermolysis bullosa simplex. J. Cell Sci. 107:765-774.

55. Morley, S.M., et al. 1995. Temperature sensitivity of the keratin cytoskeleton and delayed spreading of keratinocyte lines derived from EBS patients. J. Cell Sci. 108:3463-3471.

56. Morley, S.M., et al. 2003. Generation and characterization of epidermolysis bullosa simplex cell lines: scratch assays show faster migration with disruptive keratin mutations. Br. J. Dermatol. 149:46-58.

57. Gu, L.H., and Coulombe, P.A. 2005. Defining the properties of the nonhelical tail domain in type II keratin 5: insight from a bullous disease-causing mutation. Mol. Biol. Cell. 16:1427-1438.

58. Fuchs, E., and Coulombe, P.A. 1992. Of mice and men: genetic skin diseases of keratin. Cell. 69:899-902.

59. Stephens, K., Sybert, V.P., Wijsman, E.M., Ehrlich, P., and Spencer, A. 1993. A keratin 14 mutational hot spot for epidermolysis bullosa simplex, Dowling-Meara: implications for diagnosis. J. Invest. Dermatol. 101:240-243.

60. Cooper, D.N., and Youssouffian, H. 1988. The CpG dinucleotide and human genetic diseases. Hum. Genet. 78:151-155.

61. Ma, L., Yamada, S., Wirtz, D., and Coulombe, P.A 2001. A 'hot-spot' mutation alters the mechanical properties of keratin filament networks. Nat. Cell Biol. 3:503-506.

62. Werner, N.S., et al. 2004. Epidermolysis bullosa simplex-type mutations alter the dynamics of the keratin cytoskeleton and reveal a contribution of actin to the transport of keratin subunits. Mol. Biol. Cell. 15:990-1002.

63. Parry, D.A. 2005. Microdissection of the sequence and structure of intermediate filament chains. $A d v$. Protein Chem. 70:113-142.

64. Hatzfeld, M., and Weber, K. 1991. Modulation of keratin intermediate filament assembly by single amino acid exchanges in the consensus sequence at the C-terminal end of the rod domain. J. Cell Sci. 99:351-362.

65. Letai, A., Coulombe, P.A., and Fuchs, E. 1992. Do the ends justify the mean? Proline mutations at the ends of the keratin coiled-coil rod segment are more disruptive than internal mutations. J. Cell Biol. 116:1181-1195.

66. Hovnanian, A., et al. 1993. A missense mutation in the rod domain of keratin 14 associated with recessive epidermolysis bullosa simplex. Nat. Genet. 3:327-332.

67. Yamada, S., Wirtz, D., and Coulombe, P.A. 2003. The mechanical properties of simple epithelial keratins 8 and 18: discriminating between interfacial 
and bulk elasticities. J. Struct. Biol. 143:45-55.

68. Beil, M., et al. 2003. Sphingosylphosphorylcholine regulates keratin network architecture and viscoelastic properties of human cancer cells. Nat. Cell Biol. 5:803-811.

69. Rugg, E.L., et al. 1994. A functional "knockout" of human keratin 14. Genes Dev. 8:2563-2573.

70. Ku, N.O., and Omary, M.B. 2000. Keratins turn over by ubiquitination in a phosphorylation-modulated fashion. J. Cell Biol. 149:547-552.

71. Janig, E., Stumptner, C., Fuchsbichler, A., Denk, H., and Zatloukal, K. 2005. Interaction of stress proteins with misfolded keratins. Eur. J. Cell Biol. 84:329-339.

72. D'Alessandro, M., Russell, D., Morley, S.M., Davies, A.M., and Lane, E.B. 2002. Keratin mutations of epidermolysis bullosa simplex alter the kinetics of stress response to osmotic shock. J. Cell Sci. 115:4341-4351.

73. Liovic, M., et al. 2008. Dual-specificity phosphatases in the hypo-osmotic stress response of keratin-defective epithelial cell lines. Exp. Cell Res. 314:2066-2075.

74. Brenner, M., et al. 2001. Mutations in GFAP, encoding glial fibrillary acidic protein, are associated with Alexander disease. Nat. Genet. 27:117-120.

75. Hagemann, T.L., Connor, J.X., and Messing, A 2006. Alexander disease-associated glial fibrillary acidic protein mutations in mice induce Rosenthal fiber formation and a white matter stress response. J. Neurosci. 26:11162-11173.

76. Gu, L.H., et al. 2003. A usual frameshift and delayed termination codon mutation in keratin 5 causes a novel type of epidermolysis bullosa simplex with migratory circinate erythema. J. Invest. Dermatol. 121:482-485

77. Yoneda, K., et al. 2004. An autocrine/paracrine loop linking keratin 14 aggregates to tumor necrosis factor $\{$ alpha $\}$-mediated cytotoxicity in a keratinocyte model of epidermolysis bullosa simplex. J. Biol. Chem. 279:7296-7303.

78. Lu, H., et al. 2007. Induction of inflammatory cytokines by a keratin mutation and their repression by a small molecule in a mouse model for EBS. J. Invest. Dermatol. 127:2781-2789.

79. Lugassy, J., et al. 2008. KRT14 haploinsufficiency results in increased susceptibility of keratinocytes to TNF-alpha-induced apoptosis and causes Naegeli-Franceschetti-Jadassohn syndrome. J. Invest. Dermatol. 128:1517-1524.

80. Yoneda, K., et al. 2005. Tunel positive keratinocytes in keratin disease. J. Dermatol. Sci. 40:65-67.

81. Uttam, J., et al. 1996. The genetic basis of epidermolysis bullosa simplex with mottled pigmentation. Proc. Natl. Acad. Sci. U. S. A. 93:9079-9084

82. Horiguchi, Y., et al. 2005. Clinical heterogeneity of 1649delG mutation in the tail domain of keratin 5: a Japanese family with epidermolysis bullosa simplex with mottled pigmentation. J. Invest. Dermatol. 125:83-85.

83. Harel, A., Bergman, R., Indelman, M., and Sprecher, E. 2006. Epidermolysis bullosa simplex with mottled pigmentation resulting from a recurrent mutation in KRT14. J. Invest. Dermatol. 126:1654-1657.

84. Betz, R.C., et al. 2006. Loss-of-function mutations in the keratin 5 gene lead to Dowling-Degos disease. Am. J. Hum. Genet. 78:510-519.

85. Lugassy, J., et al. 2006. Naegeli-Franceschetti-Jadassohn syndrome and dermatopathia pigmentosa reticularis: two allelic ectodermal dysplasias caused by dominant mutations in KRT14. Am. J. Hum. Genet. 79:724-730.

86. Fitch, K.R., et al. 2003. Genetics of dark skin in mice. Genes Dev. 17:214-228.
87. McGowan, K.A., Aradhya, S., Fuchs, H., de Angelis, M.H., and Barsh, G.S. 2006. A mouse keratin 1 mutation causes dark skin and epidermolytic hyperkeratosis. J. Invest. Dermatol. 126:1013-1016.

88. Van Den Bossche, K., Naeyaert, J.M., and Lambert, J. 2006. The quest for the mechanism of melanin transfer. Traffic. 7:769-778.

89. Boissy, R.E. 2003. Melanosome transfer to and translocation in the keratinocyte. Exp. Dermatol. 12(Suppl. 2):5-12.

90. Nobuhara, S., Idea, T., Miyachi, Y., and Takahashi, K. 2003. The head domain of keratin 5 binds to a dynein light chain, the cytoplasmic cargo complex, and might be involved in the distribution of keratin filaments and melanosomes [abstract]. J. Invest. Dermatol. 121:0498a.

91. Byers, H.R., Maheshwary, S., Amodeo, D.M., and Dykstra, S. G. 2003. Role of cytoplasmic dynein in perinuclear aggregation of phagocytosed melanosomes and supranuclear melanin cap formation in human keratinocytes. J. Invest. Dermatol. 121:813-820.

92. Kantheti, P., et al. 1998. Mutation in AP-3 delta in the mocha mouse links endosomal transport to storage deficiency in platelets, melanosomes, and synaptic vesicles. Neuron. 21:111-122.

93. Styers, M.L., et al. 2004. The endo-lysosomal sorting machinery interacts with the intermediate filament cytoskeleton. Mol. Biol. Cell. 15:5369-5382.

94. Styers, M.L., Kowalczyk, A.P., and Faundez, V. 2005. Intermediate filaments and vesicular membrane traffic: the odd couple's first dance? Traffic. 6:359-365.

95. Holbrook, K.A., Wapner, R., Jackson, L., and Zaeri, N. 1992. Diagnosis and prenatal diagnosis of epidermolysis bullosa herpetiformis (Dowling-Meara) in a mother, two affected children, and an affected fetus. Prenat. Diagn. 12:725-739.

96. Rugg, E.L., et al. 2000. DNA based prenatal testing for the skin blistering disorder epidermolysis bullosa simplex. Prenat. Diagn. 20:371-377.

97. Pfendner, E.G., Nakano, A., Pulkkinen, L., Christiano, A.M., and Uitto, J. 2003. Prenatal diagnosis for epidermolysis bullosa: a study of 144 consecutive pregnancies at risk. Prenat. Diagn. 23:447-456.

98. Lewin, A.S., Glazer, P.M., and Milstone, L.M. 2005. Gene therapy for autosomal dominant disorders of keratin. J. Investig. Dermatol. Symp. Proc. 10:47-61.

99. Hengge, U.R. 2008. SMaRT technology enables gene expression repair in skin gene therapy. J. Invest. Dermatol. 128:499-500.

100.Langan, S.M., and Williams, H.C. 2008. A systematic review of randomized controlled trials of treatments for inherited forms of epidermolysis bullosa. Clin. Exp. Dermatol. 34:20-25.

101. Radoja, N., et al. 2004. Thyroid hormones and gamma interferon specifically increase K15 keratin gene transcription. Mol. Cell. Biol. 24:3168-3179.

102.El Ghalbzouri, A., Jonkman, M., Kempenaar, J., and Ponec, M. 2003. Recessive epidermolysis bullosa simplex phenotype reproduced in vitro: ablation of keratin 14 is partially compensated by keratin 17. Am. J. Pathol. 163:1771-1779.

103.Zhou, Q., et al. 2003. Keratin 20 helps maintain intermediate filament organization in intestinal epithelia. Mol. Biol. Cell. 14:2959-2971.

104.Magin, T.M., et al. 2000. Supplementation of a mutant keratin by stable expression of desmin in cultured human EBS keratinocytes. J. Cell Sci. 113:4231-4239.

105.Kirfel, J., Peters, B., Grund, C., Reifenberg, K., and Magin, T.M. 2002. Ectopic expression of desmin in the epidermis of transgenic mice permits devel- opment of a normal epidermis. Differentiation. 70.56-68.

106.Coulombe, P.A., and Wong, P. 2004. Cytoplasmic intermediate filaments revealed as dynamic and multipurpose scaffolds. Nat. Cell Biol. 6:699-706.

107. Reichelt, J., and Magin, T.M. 2002. Hyperproliferation, induction of c-Myc and 14-3-3sigma, but no cell fragility in keratin-10-null mice. J. Cell Sci. 115:2639-2650

108.McGowan, K.M., et al. 2002. Keratin 17 null mice exhibit age- and strain-dependent alopecia. Genes Dev. 16:1412-1422.

109.Tong, X., and Coulombe, P.A. 2006. Keratin 17 regulates hair follicle cycling in a TNFalpha-dependent fashion. Genes Dev. 20:1353-1364.

110.Kopan, R., and Fuchs, E. 1989. The use of retinoic acid to probe the relation between hyperproliferation-associated keratins and cell proliferation in normal and malignant epidermal cells. J. Cell Biol. 109:295-307.

111.Jiang, C.K., et al. 1993. Epidermal growth factor and transforming growth factor alpha specifically induce the activation- and hyperproliferation-associated keratins 6 and 16. Proc. Natl. Acad. Sci.U.S. A. 90:6786-6790.

112.Grachtchouk, M., et al. 2000. Basal cell carcinomas in mice overexpressing Gli2 in skin. Nat. Genet. 24:216-217.

113.Zhang, Y., Talalay, P., Cho, C.G., and Posner, G.H 1992. A major inducer of anticarcinogenic protective enzymes from broccoli: isolation and elucidation of structure. Proc. Natl. Acad. Sci. U. S. A. 89:2399-2403.

114.Zhang, Y., and Gordon, G.B. 2004. A strategy for cancer prevention: stimulation of the Nrf2-ARE signaling pathway. Mol. Cancer Ther. 3:885-893.

115.Kensler, T.W., et al. 2005. Effects of glucosinolate-rich broccoli sprouts on urinary levels of aflatoxin-DNA adducts and phanathrene tetraols in a randomized clinical trial in the He Zyuo township, Qidong, People's Republic of China. Cancer Epidemiol. Biomarkers Prev. 14:2605-2613.

116.Shapiro, T.A., et al. 2006. Safety, tolerance, and metabolism of broccoli sprout glucosinolates and isothiocyanates: a clinical phase I study. Nutr. Cancer. 55:53-62.

117. Cornblatt, B.S., et al. 2007. Preclinical and clinical evaluation of sulforaphane for chemoprevention in the breast. Carcinogenesis. 28:1485-1490.

118.Dinkova-Kostova, A.T., et al. 2007. Induction of the phase 2 response in mouse and human skin by sulforaphane-containing broccoli sprout extracts. Cancer Epidemiol. Biomarkers Prev. 16:847-851.

119. Weber, F.P. 1926. Recurrent bullous eruption on the feet in a child. Proc. R Soc. Med. 19:72-75.

120.Cockayne, E.A. 1938. Recurrent bullous eruption of the feet. Br. J. Dermatol. 50:358-366.

121. Koebner, H. 1886. Hereditare anlage zur blasendilbung (epidermolysis bullosa hereditaria). Dtsch. Med. Wochenschr. 12:21-22.

122.Dowling, G.B., and Meara, R.H. 1954. Epidermolysis bullosa resembling juvenile dermatitis herpetiformis. Br. J. Dermatol. 66:139-143.

123.Fischer, T., and Gedde-Dahl, T., Jr. 1979. Epidermolysis bullosa simplex and mottled pigmentation: a new dominant syndrome. I. Clinical and histological features. Clin. Genet. 15:228-238.

124. Dowling, G.B., and Freudenthal, W. 1938. Acanthosis nigricans. Br. J. Dermatol. 50:467-471.

125.Fransceschetti, A., and Jadassohn, W. 1954. On incontinentia pigmenti and differentiation of two syndromes appearing under the same name. Dermatologica. 108:1-28. 